\title{
2G-1 TCR Retroviral Vector-Transduced Lymphocytes
}

National Cancer Institute

\section{Source}

National Cancer Institute. 2G-1 TCR Retroviral Vector-Transduced Lymphocytes. NCI

Thesaurus. Code C82408.

A preparation of autologous human T-lymphocytes isolated from renal cell cancer (RCC) patient and transduced with 2G-1 TCR, a retroviral vector encoding the alpha and beta chains of a T-cell receptor that recognizes TNF-related apoptosis inducing ligand (TRAIL) bound to death receptor 4 (DR4), with potential immunostimulating and antineoplastic activities. After transduction, expansion in culture, and introduction into the RCC patient, 2G-1 TCR retroviral vector-transduced lymphocytes may stimulate a cytotoxic T lymphocyte (CTL) response against RCC cells with TRAIL bound to DR4 on their surfaces. TRAIL, a member of the TNF superfamily, is a homotrimeric type II membrane protein that rapidly induces oligomerization of receptor intracellular death domains and apoptosis in a variety of tumor cells when bound to its receptors; DR4 (TRAIL receptor 1), a member of the TNF receptor family, is overexpressed by a variety of malignant cell types. 